\title{
Evaluation of Thermal Hazard Properties of Low Temperature Active Azo Compound under Process Conditions for Polymer Resin in Construction Industries
}

\author{
Chia-Feng Tsai ${ }^{1, *(1)}$ and I-Jyh Wen ${ }^{2, *(1)}$ \\ 1 Graduate School of Engineering Science and Technology, National Yunlin University of Science and \\ Technology (YunTech), 123, University Rd., Sec. 3, Douliou 64002, Taiwan \\ 2 Department of Civil and Construction Engineering, National Yunlin University of Science and Technology \\ (YunTech), 123, University Rd., Sec. 3, Douliou 64002, Taiwan \\ * Correspondence: d10910205@yuntech.edu.tw (C.-F.T.); wenij@yuntech.edu.tw (I.-J.W.)
}

Citation: Tsai, C.-F.; Wen, I.-J. Evaluation of Thermal Hazard Properties of Low Temperature Active Azo Compound under Process Conditions for Polymer Resin in Construction Industries. Processes 2021, 9, 1934. https://doi.org/ $10.3390 /$ pr9111934

Academic Editor: Gergely Kali

Received: 17 September 2021

Accepted: 25 October 2021

Published: 28 October 2021

Publisher's Note: MDPI stays neutral with regard to jurisdictional claims in published maps and institutional affiliations.

Copyright: (c) 2021 by the authors. Licensee MDPI, Basel, Switzerland. This article is an open access article distributed under the terms and conditions of the Creative Commons Attribution (CC BY) license (https:/ / creativecommons.org/licenses/by/ $4.0 /)$.

\begin{abstract}
The application of polymerization initiators in a process can improve reaction efficiency and reduce energy loss. Azo compounds (azos) provide the required energy and promote polymerization for construction due to the heat release in the decomposition reaction. However, the heat release also brings related thermal hazards due to the lack of proper control. To reduce and avoid possible future hazards, the new azo initiators, 2,2'-Azobis(2-methylpropionamide)dihydrochloride (AIBA) is selected to explore the related thermal properties that are less studied by past literature. For the chemical process, its chemical reaction mechanism is extremely essential. In addition to being an influential foundation for process control, it is also used as a calculation basis for subsequent thermal hazard parameters, which is suitable for evaluating the degree of thermal hazard and emergency response. The assessment program includes kinetic model simulations and consecutive calculation on thermal safety parameters, such as $T M R_{\mathrm{ad}}$ and $T C L$ for process operations. This study combines the thermogravimetric data with the nonlinear kinetics fitting on thermogram. The fitting results are derived back to the analysis formula which corresponds to the reaction mode to obtain the elementary reaction parameters and establish the kinetics process. The runaway mode and consequent thermal hazard parameters can also be obtained.
\end{abstract}

Keywords: polymerization; construction; thermal hazard; thermal safety; kinetic

\section{Introduction}

Long-term technological improvements and related research in the polymer manufacturing industry have led to the application of various materials in the polymer area [1]. Azo compounds (azos) were originally used as the mainstream on applied solutions of dye areas, which have relied on consideration from scientific research due to its highly energetic properties.

The high energetic properties of azos facilitates the initiation of the polymerization reaction. This property is attributed to the thermal decomposition of azo compounds and the formation of radicals. Energy released helps to meet the threshold of reaction, and the reactivity of the generated free radicals has a significant role in promoting the polymerization of different types of monomers [2], such as to facilitate the fabrication of plastics for construction and water-absorbent resins. The reaction characteristic of the decomposition brings heat release accompanied by temperature rise and a large amount of gas products, which may cause equipment deformation, and if the situation is ignited after a leak occurs, it will cause a fire and explosion [3-5].

Reaction hazard characteristics [6] can be developed on the basis of real past cases; the thermal hazard [7-9] that occurred on 12 May 2016 is one example. A warehouse storing azo dyes caused a fire and damaged related facilities due to improper temperature and ignition source control. There is a large amount of evidence that in the azo processing program, 
in the initial high temperature condition caused by mis-operation or cooling failure, even if only a small part of the material generates a decomposition reaction due to its self-reaction characteristics, the heat generated with the temperature rise is enough to induce the rest of the surrounding materials to react. Therefore, temperature control to circumvent thermal runaway is an essential basis [10] for avoiding similar process disasters, and relevant safety studies should be performed. Although the thermal safety of azo compounds has been discussed in the existing literature, the progress of the manufacturing process has resulted in the pre-research of new azos for production and application. To improve the efficiency and energy saving of the process, the new initiator focuses on the lower temperature to start the polymerization reaction. However, the decomposition feature at low temperatures represents low thermal stability, the thermal safety needs to be determined. The related research on initiators that have recently been employed into practical processes is still lacking and most of the reported research in the previous literature are concentrated on the application of azo dyes. The azo initiators 2,2'-Azobis(2-methylpropionamide)dihydrochloride (AIBA) as Figure 1 used for lower temperature range which generated the decomposition reaction below $60^{\circ} \mathrm{C}[9,11,12]$, represented hazardous feature, is selected for a pioneering methodology to demonstrate the kinetics explanation in a real situation.<smiles>CC(C)(N=NC(C)(C)C(=N)N)C(=N)N</smiles>

Figure 1. The chemical structure of AIBA.

The analysis is based on the experimental data obtained by thermogravimetric analysis and the nonlinear fitting method which is used to conform with the experimental curve. The data points corresponding to the curve can be substituted into the formula to obtain the basic parameters and establish the corresponding kinetic analysis mode to connect the heat transfer of the reaction simulation. The thermal hazard of a substance is directly related to the acquisition of reaction kinetics [13]. The description of the reaction mechanism and the comprehension of parameter values [14] will be used to calculate the heat exchange between the substance itself and the external environment. The characterization of the reaction kinetics depends mostly on the activation energy $\left(E_{\mathrm{a}}\right)$, pre-exponential factor $(A)$, and the reaction equation $(f(\alpha))$ [15]. The heat release mode of the substance that confirms the safety temperature parameters is then calculated, which is used to evaluate the efficiency of the cooling system and the response time for emergency measures [16]. The overall research process is shown in Figure 2.

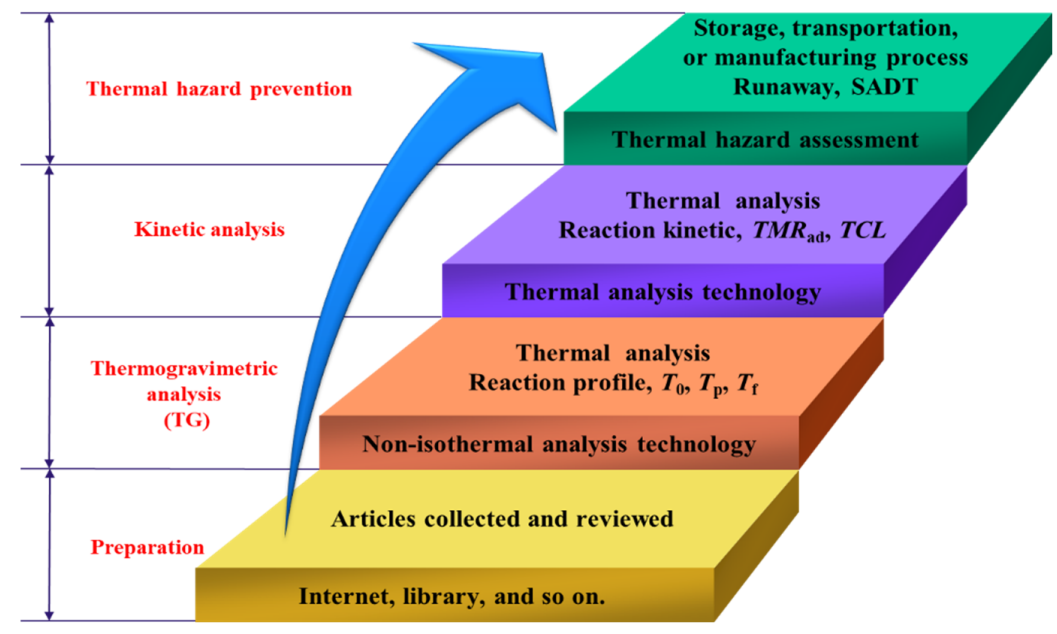

Figure 2. The chemical structure of AIBA. 


\section{Materials and Methods}

\subsection{Samples}

AIBA samples were obtained as 99.0 mass \% white powdery solid from ACE Chemical Corp., Shanghai, China. The samples were refrigerated at a low temperature and kept dry to prevent self-reaction from decomposition and deliquescence.

\subsection{Thermogravimetric Analyzer}

The Thermogravimetric analysis (TGA) from Mettler Toledo is a quantitative analysis technique that derives the transformation, kinetics, and mechanism of the overall process of the reaction through changes in sample quality under isothermal or non-isothermal heating environments. For reactive substances, combining with software technology can monitor and record changes in the quality of the sample affected by the temperature program over time. The overall testing program consisted of a furnace chamber as $0.5,1.0,2.0,4.0$, and $8.0{ }^{\circ} \mathrm{C} / \mathrm{min}[17,18]$ from 25.0 to $400.0{ }^{\circ} \mathrm{C}$ for a heating rate which vented with nitrogen $(50 \mathrm{~mL} / \mathrm{min})$ and a microbalance. The microbalance recorded the mass changes of the samples $(3.0 \pm 0.1 \mu \mathrm{g})$ on the balance through the programmer and controller.

\subsection{Basic Theory of Kinetic Model}

The $E_{\mathrm{a}}$ and $A$ have a variety of widely recognized methods under the verification of various empirical formulas and studies. However, it is relatively complicated to establish the $f(\alpha)$ [19], especially for substances with multi-stage reactions. To evaluate the $f(\alpha)$ and make the calculated results consistent with the experimental results as much as possible and simplify the calculation hypothesis, the fitting model [20] is considered the reaction process $(a)$ as it is a variable which can substitute various reaction equations for calculations to obtain the specific reaction rate $(\mathrm{d} a / \mathrm{d} t)$ as a characterization. The experimental reaction mass loss (TG) and the specific mass loss rate (dTG) caused by the reaction can be manifested as a nonlinear fitting process between the curve calculated by the numerical method and the experimental data line in the actual calculation [21]. The thermal safety software [22] combined with kinetic analysis was used to determine the decomposition characteristics of thermal hazard parameters. The thermal safety software performed nonlinear fitting TGA data based on kinetic model to calculate the hazard parameters corresponding to reaction rate under adiabatic conditions.

The reaction mode can be divided into single stage or multi-stage reaction $[16,23,24]$. The basic reaction mode can be expressed as:

$$
\frac{\mathrm{d} \alpha}{\mathrm{d} t}=k \exp \left(-\frac{E}{R T}\right) f(\alpha)
$$

The basic $f(\alpha)$ can be characterized by nth and autocatalytic reactions:

$$
f(\alpha)=\left\{\begin{array}{cc}
(1-\alpha)^{n} & \text { nth model } \\
(1-\alpha)^{n 1}\left(\alpha^{n 2}+z\right) & \text { autocatalysis model }
\end{array}\right.
$$

Exploring the multi-stage reaction can generalize the mode that does not affect each other $(\mathrm{A} \rightarrow \mathrm{B} \rightarrow \mathrm{C})$ or opposite $(\mathrm{A} \rightarrow \mathrm{B}+\ldots$ or $\mathrm{A}+\mathrm{B} \rightarrow 2 \mathrm{~B})$, which can be expressed as Equations (3) and (4), respectively:

$$
\begin{gathered}
\frac{\mathrm{d} \alpha_{1}}{\mathrm{~d} t}=k_{1} \exp \left(-\frac{E_{1}}{R T}\right) f_{1}(1-\alpha) ; \frac{\mathrm{d} \alpha_{2}}{\mathrm{~d} t}=k_{2} \exp \left(-\frac{E_{2}}{R T}\right) f_{2}\left(\alpha-\alpha_{2}\right) \\
\frac{\mathrm{d} \alpha}{\mathrm{d} t}=k_{1} \exp \left(-\frac{E_{1}}{R T}\right)(1-\alpha)^{n 1}+k_{2} \exp \left(-\frac{E_{2}}{R T}\right) \alpha^{n 2}(1-\alpha)
\end{gathered}
$$

\subsection{Extending from the Analysis of Material Dynamics to the Thermal Balance of the System}

Reaction kinetics can continue to be extended to the thermal equilibrium of systems containing substances, such as vessels. For the accumulation of many substances with 
self-reaction characteristics, the self-decomposition heat from a small part of the substances cannot release to outside systems, which results in temperature rise. If this phenomenon can be diluted by the heat conduction on the surface of the system, it can be avoided that other unreacted substances in the system are introduced into the reaction by high temperature. Otherwise, many substance reactions are triggered to form the runaway reactions. This situation of rapid temperature rise in a short time must be avoided in hazard control. The basic system heat conduction equation can be expressed as:

$$
\rho C_{\mathrm{p}} \frac{\partial T}{\partial t}=\operatorname{div}(\lambda(\operatorname{grad}(T))+W)
$$

where $\rho$ is the density, $C_{\mathrm{p}}$ is the specific heat capacity, $\lambda$ is the thermal conductivity coefficient, $T$ is the temperature, and $W$ is the heat generation due to reaction.

The basic assumption is that the initial temperature inside the system is evenly distributed with the setting of boundary conditions:

$$
\left\{\begin{array}{c}
1 s t \text { kind: } T_{\mathrm{s}}=T_{\mathrm{e}} \\
\text { 2nd kind: }-\left.\lambda \frac{\partial T}{\partial X}\right|_{\mathrm{s}}=q_{\mathrm{e}} \\
\text { 3rd kind: }\left.\lambda \frac{\partial T}{\partial X}\right|_{\mathrm{s}}=U\left(T_{\mathrm{s}}-T_{\mathrm{e}}\right)
\end{array}\right.
$$

where $x$ is the outer unit normal on the boundary, subscripts $s$ and $e$ denote the surface and environment, respectively, and $U$ is the heat transfer coefficient.

\subsection{Safety Operation and Related Evaluation Parameters of Actual Manufacturing Process}

The reaction rate is always a crucial factor for efficiency in the chemical process. However, the reaction rate still has its limits due to safety considerations. Process deviations, such as incorrect operations causing the process temperature to exceed the tolerance limit, and the rapid increase in reaction rate, drives a large amount of heat release with temperature rise and will eventually lead to process equipment damage, leakage, and even fire and explosion. In the above-mentioned classic thermal runaway scenario chemical process, if the initial heat can be effectively ventilated or cooled by the process staff or system which can appropriately respond by adequate time, the process can be adjusted in normal operation. Sufficient respond time also means that if heat accumulation is formed in the initial stage, under safety measures, the hazard can still be eliminated in the early stage. Therefore, the reaction process and time efficiency related parameters are extremely significant in the normal operation and the emergency response process, which can be characterized by the current time required for the estimated substance to reach the maximum reaction rate $\left(T M R_{\mathrm{ad}}\right.$ And $\left.T M R_{\mathrm{iso}}\right)$.

$T M R_{\text {ad }}$ and $T M R_{\text {iso }}$ can be obtained through adiabatic and isothermal experiments, but the experimental equipment is expensive, and the procedures are complicated. To improve the efficiency in industrial applications, the TGA, which is convenient and widely approved by research, can be analyzed by the changes in pattern of reactions with time to the actual process situation from numerical methods. $T M R_{\mathrm{ad}}$ was discussed by Kossoy and Akhmetshin's thermodynamic measurement [25] where the influence of reaction rate on hazard was evaluated. As seen in Wang et al. [26], $T M R_{\mathrm{ad}}$ can provide a basis for initiating emergency measures to reduce the rate of thermal runaway reactions. Therefore, $T M R_{\mathrm{ad}}$ is a useful indicator for determining response time. $T M R_{\mathrm{ad}}$ can be evaluated from the following calculation modes [27]:

When a substance is decomposed or reacted in a batch reactor, the heat balance can be conveyed as Equation (7).

$$
\dot{Q_{\text {in }}}-\dot{Q}_{\text {out }}+\dot{Q}_{\mathrm{r}}=\frac{\Delta Q}{\Delta t}
$$


The thermal equilibrium of the exothermic reaction obtained by calorimetry from Equation (7) is derived as Equation (8).

$$
U A\left(T_{\mathrm{e}}-T_{\mathrm{s}}\right)+M_{\mathrm{s}}\left(-\Delta H_{\mathrm{d}}\right) \frac{\mathrm{d} \alpha}{\mathrm{d} t}=M_{\mathrm{s}} C_{\mathrm{p}, \mathrm{s}} \frac{\mathrm{d} T_{\mathrm{s}}}{\mathrm{d} t}+M_{\mathrm{c}} C_{\mathrm{p}, \mathrm{c}} \frac{\mathrm{d} T_{\mathrm{c}}}{\mathrm{d} t}
$$

where $U, A, T_{\mathrm{e}}, T_{\mathrm{s}}, T_{\mathrm{c}}, M_{\mathrm{s}}, C_{\mathrm{p}, \mathrm{s}}$, and $C_{\mathrm{p}, \mathrm{c}}$ are heat transfer coefficient, wetted surface area, environment temperature, sample temperature, test cell temperature, sample's heat capacity, and test cell's heat capacity, respectively.

Equation (9) indicates that the sample and the test cell are in thermal equilibrium.

$$
\frac{\mathrm{d} T_{\mathrm{c}}}{\mathrm{d} t}=\frac{\mathrm{d} T_{\mathrm{s}}}{\mathrm{d} t}=\frac{\mathrm{d} T}{\mathrm{~d} t}
$$

Assume that the value of $\lambda$ of the sample generating heat in adiabatic environment is equal to 0 . The relationship between time and temperature in adiabatic system is constructed by integrating Equations (8) and (9).

$$
\frac{\mathrm{d} T}{\mathrm{~d} t}=\frac{M_{\mathrm{s}} C_{\mathrm{p}, \mathrm{s}}}{M_{\mathrm{c}} C_{\mathrm{p}, \mathrm{s}}+M_{\mathrm{s}} C_{\mathrm{p}, \mathrm{s}}} \frac{-\Delta H_{\mathrm{d}}}{C_{\mathrm{p}, \mathrm{s}}} \frac{\mathrm{d} \alpha}{\mathrm{d} t}
$$

In addition, the phi value $(\Phi)$ and $\Delta T_{\mathrm{ad}}$ can read as Equations (11) and (12).

$$
\begin{gathered}
\Phi=\frac{M_{\mathrm{s}} C_{\mathrm{p}, \mathrm{s}}+M_{\mathrm{s}} C_{\mathrm{p}, \mathrm{s}}}{M_{\mathrm{c}} C_{\mathrm{p}, \mathrm{s}}} \\
\Delta T_{\mathrm{ad}}=\frac{-\Delta H_{\mathrm{d}}}{C_{\mathrm{p}, \mathrm{s}}}
\end{gathered}
$$

Then, Equation (11) can be rearranged as Equation (13).

$$
\frac{\mathrm{d} T}{\mathrm{~d} t}=\frac{1}{\Phi} \Delta T_{\mathrm{ad}} \frac{\mathrm{d} \alpha}{\mathrm{d} t}
$$

Therefore, when the initial temperature and $\Phi$ are defined, the numerical integration of $\mathrm{d} T / \mathrm{d} t$ can be used to predict $T M R_{\mathrm{ad}}$.

\subsection{Thermal Stability on Storage Condition}

Based on the assessment of the reactive hazard of the substance, the subsequent determination of storage and transportation hazard can be observed. According to the United Nations standard "Recommendation on the Transport of Dangerous Goods" (TDG) [28], the packaging of a substance is related to its heat sensitivity and stability. The evaluation method can be based on self-accelerating temperature on decomposition for process control and emergency. However, the test methods proposed by TDG [29] all have their use consideration requirements and a large cost [30]. Combining the material dynamics and the system heat exchange model, the temperature parameters, which the additional actual evaluation measures is not required, can be constructed [31-34]:

$$
\frac{\mathrm{d} T}{\mathrm{~d} t}=\frac{\lambda}{\rho C_{\mathrm{p}}}\left(\frac{\partial^{2} T}{\partial x^{2}}+\frac{g}{r} \frac{\partial T}{\partial x}\right)+\frac{-\Delta H_{\mathrm{d}}}{C_{\mathrm{p}}} \frac{\mathrm{d} \alpha}{\mathrm{d} t}
$$

where $C_{\mathrm{p}}$ is the sample heat capacity, $\lambda$ is the thermal conductivity, $\rho$ is the density of AIBA, $x$ is the package radius, and $g$ is a geometry factor that varies by the type of packaging. $\Delta H_{\mathrm{d}}$ and $\mathrm{d} \alpha / \mathrm{d} t$ are described by TGA and kinetics model [30,32], respectively. The thermal hazard on runaway reaction and enhancement process can be defined by the possible hazardous properties corresponding to changes in the temperature range by decomposition [30]. When the temperature exceeds the decomposition temperature at the initial stage of runaway reaction, the temperature increases continuously with the 
release of reaction heat, which is not suitable for storage and transportation. As more substances participate in the reaction, the temperature increases in a short time and shows a sharp upward trend of the inflection point on the temperature versus time curve, which is required for emergency measures to deal with possible thermal hazards. In addition, from the impact of reaction rate on process hazards, if a large number of substances decompose in a short time, the possibility of process hazards will increase. When the reaction consumes the reactant within a specific temperature range, use the estimated time (TCL) to consume a certain amount of material as the basis for evaluating the thermal hazard.

\section{Results}

\subsection{Experiment Data Curve Fitting and Derivation of Related Reaction Kinetic Parameters}

The experimental data curve is non-linearly fitted by applying reaction kinetic simulation. The fitted scenario is divided into $T G$ and dTG signal curve and the calculated result is shown in Figure 3. From the mass loss shown by the experimental curve, it can be seen that AIBA has three stages of reaction, caused in different intervals of material consumption where the reaction temperature is listed in Table 1. On this foundation, the reaction kinetics is deduced, and the experimental curves are fitted by the multi-stage model. Comparing the calculated values with the actual experimental results and gradually optimizing the degree of fitting, the evaluation results are beneficial to determine the operation mode of the process and the temperature control. The reaction parameters, such as reaction rate and activation energy, can be used as the basis for verifying the actual operation and as the source for estimating the mode of the overall reaction system, which are shown in Figures 4 and 5 and Table 2.
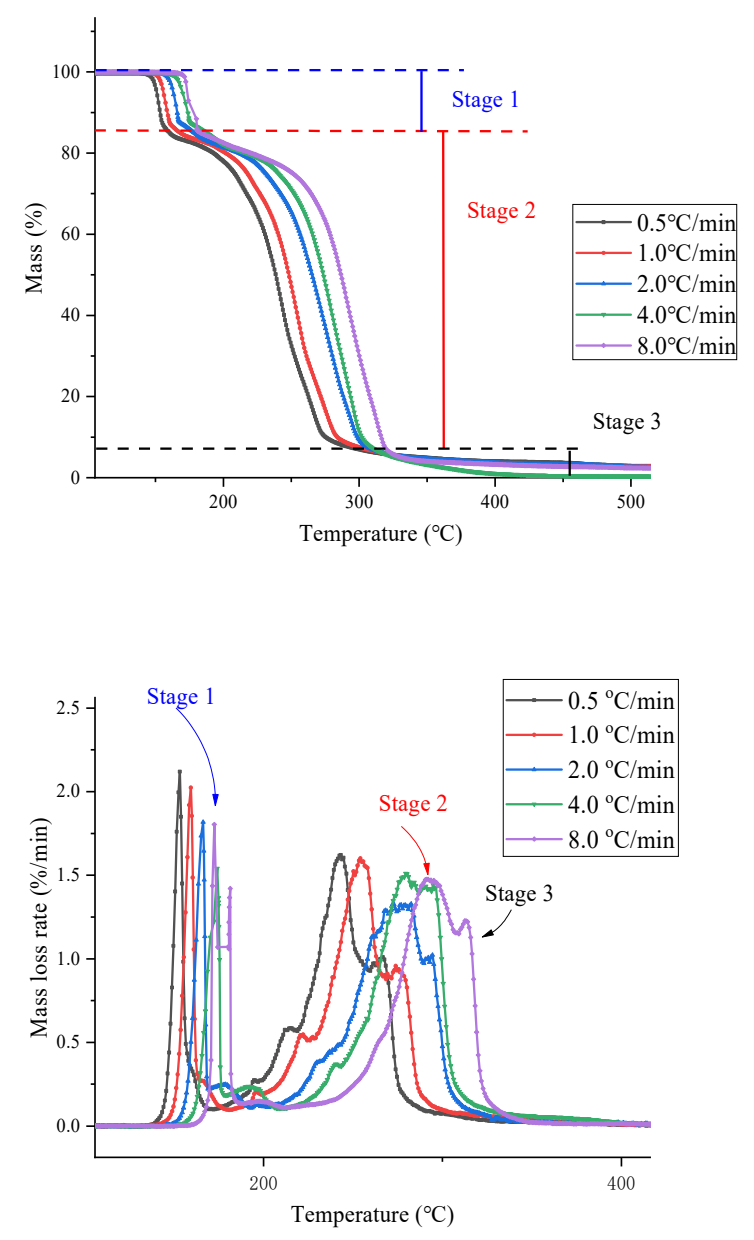

Figure 3. Mass loss and mass loss rate of AIBA by TGA results with different heating rates at $0.5,1.0$, $2.0,4.0$, and $8.0^{\circ} \mathrm{C} / \mathrm{min}$. 
Table 1. Non-isothermal data by TGA tests for 98 mass $\%$ AIBA at $0.5,1.0,2.0,4.0$, and $8.0^{\circ} \mathrm{C} / \mathrm{min}$.

\begin{tabular}{ccccc}
\hline \multirow{3}{*}{$\left({ }^{\circ} \mathbf{C} / \mathbf{m i n}\right)$} & $\begin{array}{r}\boldsymbol{T}_{\mathbf{0}} \text { for } \mathbf{1 s t} \text { Reaction } \\
\left({ }^{\circ} \mathrm{C}\right)\end{array}$ & $\begin{array}{c}\boldsymbol{T}_{\mathbf{0}} \text { for } 2 \text { nd Reaction } \\
\left({ }^{\circ} \mathbf{C}\right)\end{array}$ & $\begin{array}{c}\boldsymbol{T}_{\mathbf{0}} \text { for 3rd Reaction } \\
\left({ }^{\circ} \mathbf{C}\right)\end{array}$ \\
\cline { 2 - 5 } AIBA & 0.5 & 146 & 158 & 276 \\
& 1.0 & 150 & 166 & 289 \\
& 2.0 & 152 & 180 & 306 \\
& 4.0 & 156 & 181 & 308 \\
& 8.0 & 158 & 186 & 319 \\
\hline
\end{tabular}

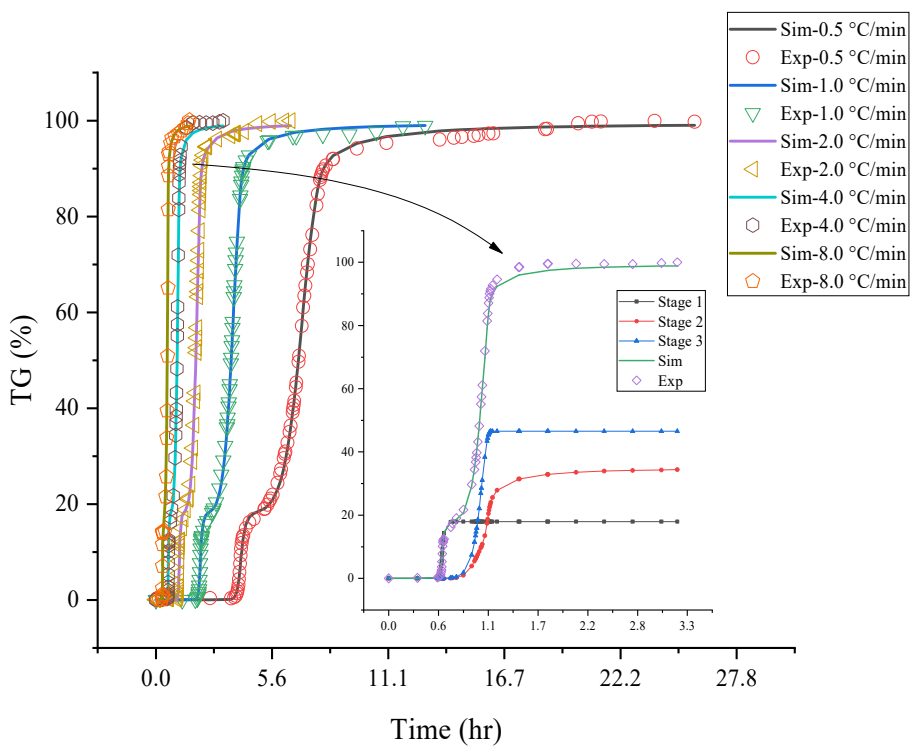

Figure 4. Mass loss of AIBA between TGA and nonlinear fitting results which contained multi-stage reactions by analyzing the experimental and simulated values of a single heating rate $4.0^{\circ} \mathrm{C} / \mathrm{min}$ along with other heating rates at $0.5,1.0,2.0$, and $8.0^{\circ} \mathrm{C} / \mathrm{min}$.

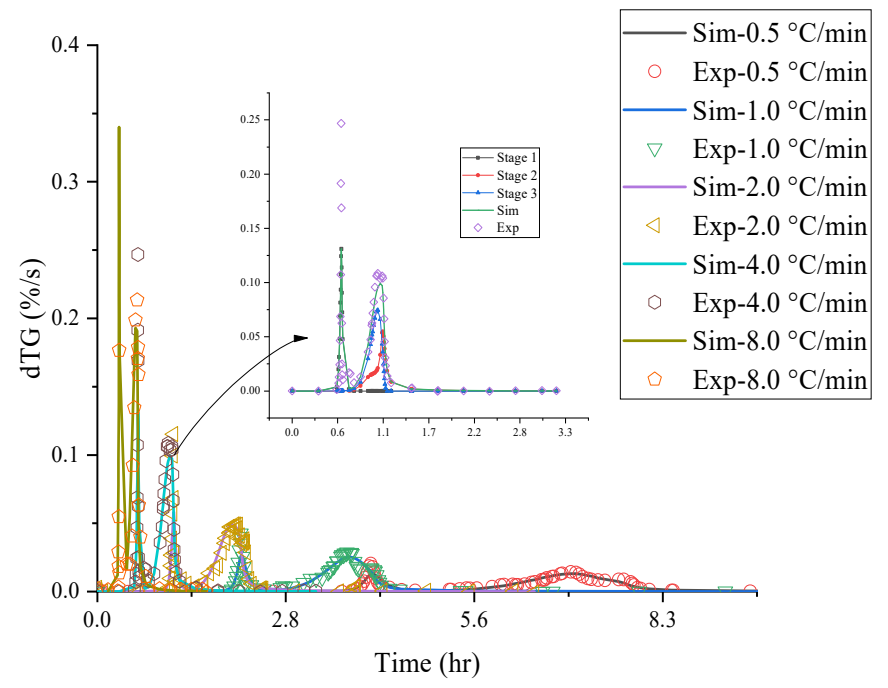

Figure 5. Mass loss rate of AIBA between TGA and nonlinear fitting results which contained multi-stage reactions by analyzing the experimental and simulated values of a single heating rate $4.0^{\circ} \mathrm{C} / \mathrm{min}$ along with other heating rates at $0.5,1.0,2.0$, and $8.0^{\circ} \mathrm{C} / \mathrm{min}$. 
Table 2. Thermokinetic parameters evaluation results of the AIBA.

\begin{tabular}{|c|c|c|c|c|c|c|c|}
\hline \multirow{2}{*}{ Substance } & \multirow{2}{*}{ Reaction Form } & \multirow{2}{*}{$\begin{array}{c}\text { Parameter } \\
\text { Units }\end{array}$} & \multirow{2}{*}{$\begin{array}{c}\ln \left(\mathbf{k}_{\mathbf{0}}\right) \\
\ln (1 / \mathrm{s})\end{array}$} & \multirow{2}{*}{$\begin{array}{c}E_{\mathrm{a}} \\
\mathrm{kJ} / \mathrm{mol}\end{array}$} & n1 & n2 & \multirow{2}{*}{$\begin{array}{c}T G \\
\%\end{array}$} \\
\hline & & & & & \multicolumn{2}{|c|}{ Dimensionless } & \\
\hline \multirow{3}{*}{ AIBA } & \multirow{3}{*}{ Auto } & 1st stage & $47.43 \pm 0.1$ & $188.32 \pm 0.03$ & $1.70 \pm 0.01$ & $0.69 \pm 0.01$ & $17.92 \pm 0.5$ \\
\hline & & 2nd stage & $36.42 \pm 0.1$ & $155.17 \pm 0.03$ & $7.35 \pm 0.01$ & $7.18 \pm 0.01$ & $34.81 \pm 0.5$ \\
\hline & & 3rd stage & $21.18 \pm 0.1$ & $122.73 \pm 0.03$ & $0.75 \pm 0.01$ & $0.08 \pm 0.01$ & $46.35 \pm 0.5$ \\
\hline
\end{tabular}

\subsection{Thermal Hazard Evaluation}

The safety characteristics of storage, transportation, and reaction are shown in Figure 6. From the change of $T C L$ value, when the temperature is $>110^{\circ} \mathrm{C}$, the consumption of AIBA is $>60 \%$ due to reaction within 1 day. In the actual storage process operation, the awareness of external fire prevention and firefighting measures should be taken, but additional cooling or rigorous temperature control are less needed.

The analysis result between reaction rate and time is shown in Figure 6. In the actual process, there needs to be a trade-off between the reaction rate to improve efficiency and the balance between the safe control process. The higher reaction rate speeds up the process, while contrarily, the temperature and pressure rise caused by the heat and gas products released by the reaction in the system must be restrained to a certain extent to avoid runaway reactions. In addition, corresponding safety measures must be taken at the development stage of potential hazards, such as: excessive reaction rate, large amounts of substances participating in the reaction, and the resulting rapid temperature rise. According to $T M R_{\mathrm{ad}}$ analysis, when the temperature is $>119^{\circ} \mathrm{C}$, the $T M R_{\mathrm{ad}}$ of AIBA is shorter. If the process can be kept in a temperature environment with a long $T M R_{\mathrm{ad}}$, it means that there is enough time to modify and stabilize the process, and to define the conditions for the influence of instability or thermal runaway on the process.

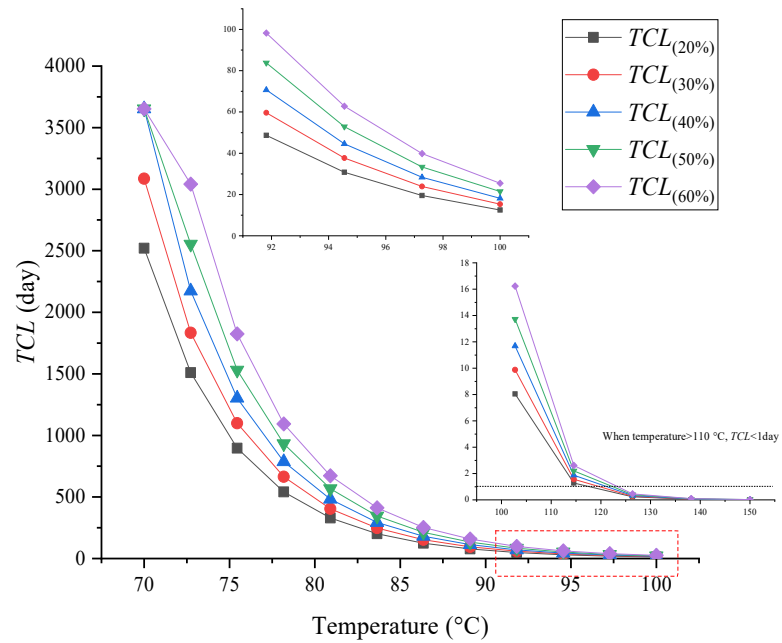

(a)

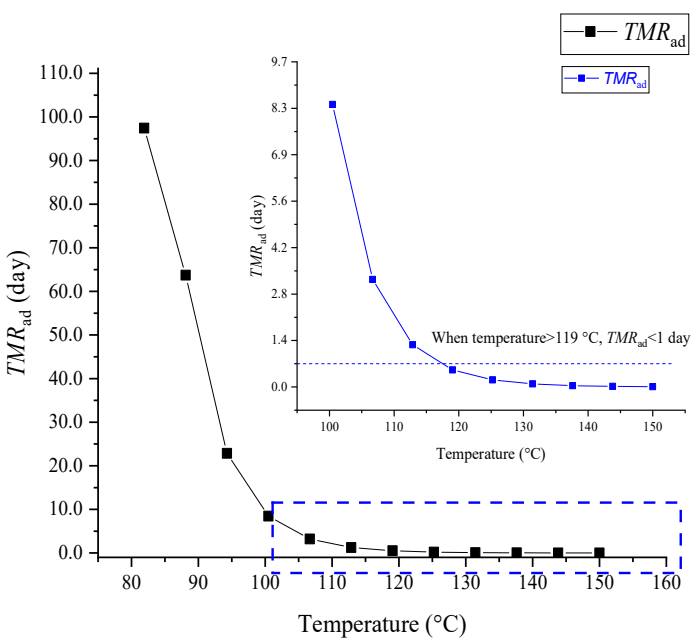

(b)

Figure 6. Simulation results of AIBA for (a) TCL and (b) $T M R_{\mathrm{ad}}$ under different ambient temperatures from heating rate of $4.0^{\circ} \mathrm{C} / \mathrm{min}$.

\subsection{Runaway Reaction of AIBA}

The description of kinetics combined with the calculation of the system's external heat exchange is used to evaluate the heat release behavior of a substance at a specific external temperature. The setting scenarios of the external environment were divided into process temperature that were high or the fire source was far away, and 120, 140, and $160{ }^{\circ} \mathrm{C}$ when the process temperature continued to rise or the heat source was connected until temperatures reached the onset temperature. The temperature parameter evaluation 
mode can be used for the hazard analysis of the process reaction, which was used to ensure safe process conditions and establish the safety system design of the process. The basic parameters of AIBA and external packaging are described in Table 3.

Table 3. Physical parameters of AIBA and packages for AIBA.

\begin{tabular}{|c|c|c|c|c|c|c|c|}
\hline Material & Size $(\mathrm{cm})$ & $\begin{array}{c}\text { Shell } \\
\text { Thickness } \\
(\mathrm{mm})\end{array}$ & $\begin{array}{c}\text { Filling } \\
\text { Height }(\mathrm{cm})\end{array}$ & $\begin{array}{l}\text { Density } \\
\text { (g/cm) }\end{array}$ & $\begin{array}{c}\text { Specific Heat } \\
\text { Capacity } \\
(\mathrm{J} /(\mathrm{g} \mathrm{K}))\end{array}$ & $\begin{array}{l}\text { Thermal } \\
\text { Conductivity } \\
\text { Coefficient } \\
(\mathrm{W} /(\mathrm{m} \mathrm{K}))\end{array}$ & $\begin{array}{c}\text { Heat } \\
\text { Transfer } \\
\text { Coefficient } \\
\left(\mathrm{W} /\left(\mathrm{m}^{2} \cdot \mathrm{K}\right)\right)\end{array}$ \\
\hline AIBA & - & - & - & 0.735 & 2.0 & 0.95 & 10 \\
\hline $25 \mathrm{~kg}$ Box & $\begin{array}{c}\mathrm{L} \times \mathrm{W} \times \mathrm{H} \\
29 \times 39 \times 46\end{array}$ & 5.0 & 35 & 0.75 & 1.7 & 0.3 & 2.2 \\
\hline
\end{tabular}

AIBA under different temperature circumstances from the set external environment temperature due to heat transfer to the inside of the system caused the temperature to continue to grow and eventually caused the temperature change when runaway reaction was shown in Figure 7. When the temperature exceeded $120^{\circ} \mathrm{C}$, the decomposition reaction led to the occurrence of runaway reaction. However, AIBA did not produce runaway reactions at temperatures $<100{ }^{\circ} \mathrm{C}$. The simulation showed that the packaging form has little effect on the thermal safety of AIBA, and the environmental temperature had a deeper influence on the thermal safety. In the actual process, the storage of AIBA did not require additional cooling, but fire alarms need to be guarded to prevent heat from promoting uncontrolled reactions. The AIBA had the characteristics of active decomposition reaction for high temperature environment which the temperature monitoring required for the reaction process. The fast reaction speed will still cause AIBA to generate thermal runaway when the temperature changes slightly. The time required for thermal runaway in high temperature environments is reduced. In the actual production process, AIBA recommends refrigeration and prevention of deterioration. The active decomposition reaction process in the chemical industry is usually carried out in a high-temperature environment. If the progress of the reaction is not adequately monitored, due to the extremely fast reaction speed, even slight temperature changes may cause thermal runaway.

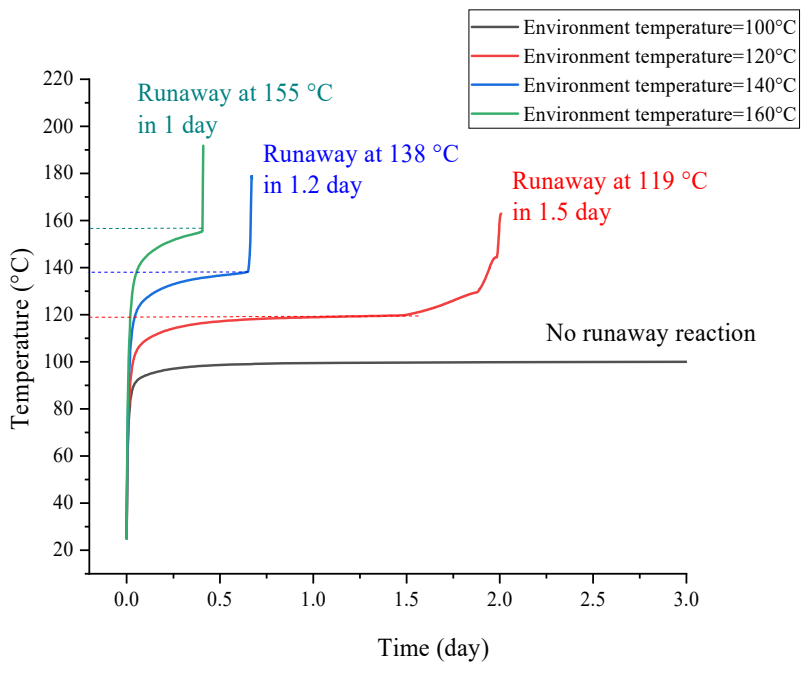

(a)

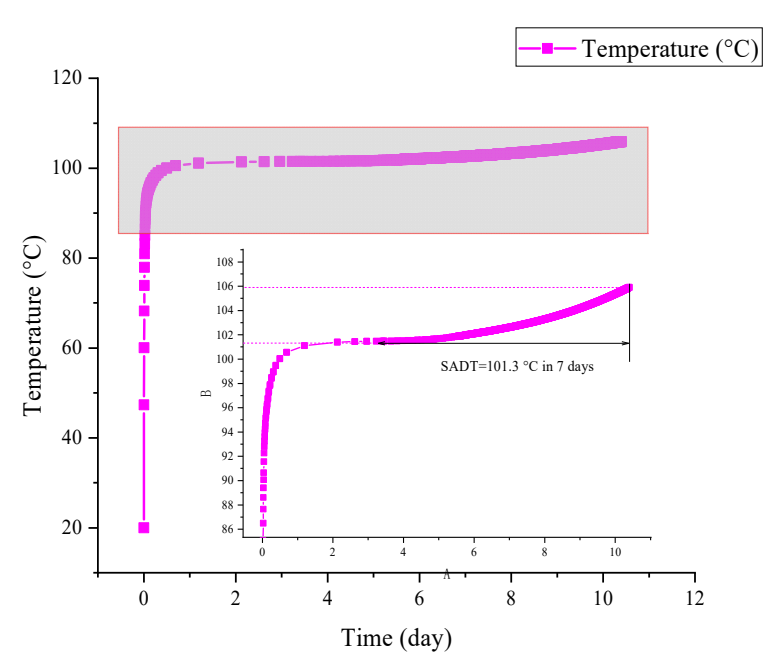

(b)

Figure 7. Simulation results of runaway reaction of the AIBA with a $20.0 \mathrm{~kg}$ box package at different ambient temperatures (a) and SADT (b). 


\section{Discussion}

The non-isothermal TGA experiment pointed out the potential reaction mode of AIBA and used it as a basis for numerical analysis. The nonlinear fitting calculation kinetic model curve is compared with the experimental data of AIBA, and the kinetic parameters are inversely deduced to predict the exothermic behavior of large-scale substances and the related heat transfer. Simulation analysis is aimed to reduce tedious and expensive experiments. Calculating the reaction behavior of substances in different external environments in simulation is completed by the prediction of thermal hazards which provided safety measures in actual situations.

Mathematical methods to analyze the thermal decomposition parameters of AIBA, such as $T C L$ and $T M R_{\mathrm{ad}}$ show that if the temperature reaches $110^{\circ} \mathrm{C}$ the thermal stability of AIBA will be affected, and when it exceeds $100^{\circ} \mathrm{C}$ the thermal stability of storage condition will further decrease. Therefore, it is a necessary measure and equipment requirement for AIBA to deal with fire protection during application.

Author Contributions: Methodology, C.-F.T. and I.-J.W.; validation, C.-F.T. and I.-J.W.; writing, C.-F.T.; writing-review and editing, I.-J.W.; supervision, I.-J.W. All authors have read and agreed to the published version of the manuscript.

Funding: This research received no external funding.

Institutional Review Board Statement: Not applicable.

Informed Consent Statement: Not applicable.

Data Availability Statement: The data presented in this study are available in all tables and figures of this article.

Acknowledgments: The authors are grateful to the technical support from National Yunlin University of Science and Technology.

Conflicts of Interest: The authors declare no conflict of interest.

\section{References}

1. Liu, S.H.; Cao, C.R.; Lin, W.C.; Shu, C.M. Experimental and numerical simulation study of the thermal hazards of four azo compounds. J. Hazard. Mater. 2019, 365, 164-177. [CrossRef]

2. Dubikhin, V.; Knerel'man, E.; Manelis, G.; Nazin, G.; Prokudin, V.; Stashina, G.; Chukanov, N.; Shastin, A. Thermal decomposition of azobis (isobutyronitrile) in the solid state. Cage effect. Recombination and disproportionation of cyanoisopropyl radicals. Dokl. Phys. Chem. 2012, 446, 171-175. [CrossRef]

3. Dou, Z.; Jiang, J.C.; Wang, Z.R.; Zhao, S.P.; Yang, H.Q.; Mao, G.B. Kinetic analysis for spontaneous combustion of sulfurized rust in oil tanks. J. Loss Prev. Process Ind. 2014, 32, 387-392. [CrossRef]

4. Dou, Z.; Jiang, J.C.; Zhao, S.P.; Zhang, W.X.; Ni, L.; Zhang, M.G.; Wang, Z.R. Analysis on oxidation process of sulfurized rust in oil tank. J. Therm. Anal. Calorim. 2017, 128, 125-134. [CrossRef]

5. Liu, S.H.; Lin, W.C.; Hou, H.Y.; Shu, C.M. Comprehensive runaway kinetic analysis and validation of three azo compounds using calorimetric approach and simulation. J. Loss Prev. Process Ind. 2017, 49, 970-982. [CrossRef]

6. Kandelhard, F.; Georgopanos, P. Predici as a Polymer Engineers' Tool for the Synthesis of Polymers via Anionic Polymerization. Ind. Eng. Chem. Res. 2021, 60, 11373-11384. [CrossRef]

7. Berdouzi, F.; Villemur, C.; Olivier Maget, N.; Gabas, N. Dynamic simulation for risk analysis: Application to an exothermic reaction. Process Saf. Environ. Prot. 2018, 113, 149-163. [CrossRef]

8. Cao, C.R.; Liu, S.H.; Shu, C.M. Reaction simulation of multistage evaluations for AMBN based on DSC experiments. Thermochim. Acta 2018, 661, 18-26. [CrossRef]

9. Liu, S.H.; Lin, W.C.; Xia, H.; Hou, H.Y.; Shu, C.-M. Combustion of 1-butylimidazolium nitrate via DSC, TG, VSP2, FTIR, and GC/MS: An approach for thermal hazard, property and prediction assessment. Process Saf. Environ. Prot. 2018, 116, 603-614. [CrossRef]

10. Kandelhard, F.; Schuldt, K.; Schymura, J.; Georgopanos, P.; Abetz, V. Model-Assisted Optimization of RAFT Polymerization in Micro-Scale Reactors-A Fast Screening Approach. Macromol. React. Eng. 2021, 15, 2000058. [CrossRef]

11. Chiang, C.L.; Liu, S.H.; Cao, C.R.; Hou, H.Y.; Shu, C.M. Multiapproach thermodynamic and kinetic characterization of the thermal hazards of 2, 2'-azobis (2-methylpropionate) alone and when mixed with several solvents. J. Loss Prev. Process Ind. 2018, 51, 150-158. [CrossRef] 
12. Liu, S.H.; Cao, C.R.; Lin, Y.C.; Shu, C.M. Using thermal analysis and kinetic calculation method to assess the thermal stability of 2,2'-azobis-(2-methylbutyronitrile). J. Therm. Anal. Calorim. 2018, 131, 545-553. [CrossRef]

13. Martín-Lara, M.; Blázquez, G.; Zamora, M.; Calero, M. Kinetic modeling of torrefaction of olive tree pruning. Appl. Therm. Eng. 2017, 113, 1410-1418. [CrossRef]

14. Li, X.R.; Koseki, H.; Iwata, Y.; Mok, Y.S. Decomposition of methyl ethyl ketone peroxide and mixtures with sulfuric acid. J. Loss Prev. Process Ind. 2004, 17, 23-28. [CrossRef]

15. Zhu, H.; Liu, N. Kinetic analysis based on the kinetic compensation effect and optimization calculation. Thermochim. Acta 2020, 690, 178686. [CrossRef]

16. Gonzales, N.O.; Levin, M.E.; Zimmerman, L.W. The reactivity of sodium borohydride with various species as characterized by adiabatic calorimetry. J. Hazard. Mater. 2007, 142, 639-646. [CrossRef]

17. Liu, S.H.; Shu, C.M. Advanced technology of thermal decomposition for AMBN and ABVN by DSC and VSP2. J. Therm. Anal. Calorim. 2015, 121, 533-540. [CrossRef]

18. Liu, S.H.; Hou, H.Y.; Shu, C.M. Thermal hazard evaluation of the autocatalytic reaction of benzoyl peroxide using DSC and TAM III. Thermochim. Acta 2015, 605, 68-76. [CrossRef]

19. Chen, W.C.; Shu, C.M. Prediction of thermal hazard for TBPTMH mixed with BPO through DSC and isoconversional kinetics analysis. J. Therm. Anal. Calorim. 2016, 126, 1937-1945. [CrossRef]

20. Kossoy, A.A.; Sheinman, I.Y. Evaluating Thermal Explosion Hazard by Using Kinetics-Based Simulation Approach. Process Saf. Environ. Prot. 2004, 82, 421-430. [CrossRef]

21. Kossoy, A.A.; Benin, A.I.; Akhmetshin, Y.G. An advanced approach to reactivity rating. J. Hazard. Mater. 2005, 118, 9-17. [CrossRef]

22. ChemInform Saint-Petersburg (CISP), L. Thermal Safety Software, Retrieved. 2021. Available online: http://www.cisp.spb.ru (accessed on 27 October 2021).

23. Andreozzi, R.; Caprio, V.; Somma, I.D.; Sanchirico, R. Kinetic and safety assessment for salicylic acid nitration by nitric acid/acetic acid system. J. Hazard. Mater. 2006, 134, 1-7. [CrossRef]

24. Kossoy, A.A.; Akhmetshin, Y.G. Identification of kinetic models for the assessment of reaction hazards. Process Saf. Prog. 2007, 26, 209-220. [CrossRef]

25. Wang, S.Y.; Kossoy, A.A.; Yao, Y.D.; Chen, L.P.; Chen, W.H. Kinetics-based simulation approach to evaluate thermal hazards of benzaldehyde oxime by DSC tests. Thermochim. Acta 2017, 655, 319-325. [CrossRef]

26. Roduit, B.; Folly, P.; Sarbach, A.; Berger, B.; Brogli, F.; Mascarello, F.; Schwaninger, M.; Glarner, T.; Irle, E.; Tobler, F. Estimation of time to maximum rate under adiabatic conditions (TMRad) using kinetic parameters derived from DSC-investigation of thermal behavior of 3-methyl-4-nitrophenol. Chem. Propel. Polym. Mater. 2011, 1, 84-93.

27. United Nations. Recommendations on the Transport of Dangerous Goods: Model Regulations, 20th Revised ed.; United Nations Publications: New York, NY, USA, 2018; Volume 1.

28. United Nations. Recommendations on the Transport of Dangerous Goods: Manual of Tests and Criteria, 6th Revised ed.; United Nations Publications: New York, NY, USA, 2018. [CrossRef]

29. Kossoy, A.A.; Sheinman, I.Y. Comparative analysis of the methods for SADT determination. J. Hazard. Mater. 2007, 142, 626-638. [CrossRef]

30. Steensma, M.; Schuurman, P.; Malow, M.; Krause, U.; Wehrstedt, K.D. Evaluation of the validity of the UN SADT H.4 test for solid organic peroxides and self-reactive substances. J. Hazard. Mater. 2005, 117, 89-102. [CrossRef]

31. Lv, J.; Chen, L.; Chen, W.; Gao, H.; Peng, M. Kinetic analysis and self-accelerating decomposition temperature (SADT) of dicumyl peroxide. Thermochim. Acta 2013, 571, 60-63. [CrossRef]

32. Malow, M.; Wehrstedt, K.D. Prediction of the self-accelerating decomposition temperature (SADT) for liquid organic peroxides from differential scanning calorimetry (DSC) measurements. J. Hazard. Mater. 2005, 120, 21-24. [CrossRef]

33. Li, X.R.; Koseki, H. SADT prediction of autocatalytic material using isothermal calorimetry analysis. Thermochim. Acta 2005, 431, 113-116. [CrossRef]

34. Kossoy, A.A.; Belokhvostov, V.M.; Koludarova, E.Y. Thermal decomposition of AIBN: Part D: Verification of simulation method for SADT determination based on AIBN benchmark. Thermochim. Acta 2015, 621, 36-43. [CrossRef] 